\title{
Failed back surgery syndrome: current perspectives
}

\author{
This article was published in the following Dove Press journal: \\ Journal of Pain Research \\ 7 November 2016 \\ Number of times this article has been viewed
}

\author{
Zafeer Baber \\ Michael A Erdek \\ Division of Pain Medicine, \\ Department of Anesthesiology and \\ Critical Care Medicine, Johns Hopkins \\ University School of Medicine, \\ Baltimore, MD, USA
}

\begin{abstract}
The treatment of failed back surgery syndrome (FBSS) can be equally challenging to surgeons, pain specialists, and primary care providers alike. The onset of FBSS occurs when surgery fails to treat the patient's lumbar spinal pain. Minimizing the likelihood of FBSS is dependent on determining a clear etiology of the patient's pain, recognizing those who are at high risk, and exhausting conservative measures before deciding to go into a revision surgery. The workup of FBSS includes a thorough history and physical examination, diagnostic imaging, and procedures. After determining the cause of FBSS, a multidisciplinary approach is preferred. This includes pharmacologic management of pain, physical therapy, and behavioral modification and may include therapeutic procedures such as injections, radiofrequency ablation, lysis of adhesions, spinal cord stimulation, and even reoperations.
\end{abstract}

Keywords: back pain, back pain with radiation, back pain without radiation, low back pain, spinal cord stimulation, review, pain disorder

\section{Introduction}

Back pain is a highly prevalent condition that can have a tremendous social, financial, and psychological impact on a patient's life. Low back pain is a worldwide problem, with an estimated $9.4 \%$ global incidence, creating more disability than any other condition in the world. ${ }^{1}$ Prevalence of low back pain increases with age, so it is understandable that there is an increasing rate of surgeries to treat back pain in accordance with an aging population demographic. It is estimated that from 2000 to 2007, the total number of adults in the United States with chronic back pain increased by $64 \%$ (from 7.8 million to 12.8 million) with a mean age increasing from 48.5 to 52.2 years. ${ }^{2}$ Considering the significant increase in the prevalence of back pain over time, it is understandable that there are similar trends in increasing rates of surgeries to treat it. Between 1998 and 2008, the annual number of hospital discharges for primary lumbar fusions increased by $170.9 \%$ from 77,682 to 210,407 . During the same period, the rate of laminectomies increased by $11.3 \%$ from 92,390 to 107,790 (Table 1). ${ }^{3}$ However, sometimes surgery fails to provide relief or provides only temporary relief of the patient's pain. The International Association for the Study of Pain defines failed back surgery syndrome (FBSS) as:

Lumbar spinal pain of unknown origin either persisting despite surgical intervention or appearing after surgical intervention for spinal pain originally in the same topographical location. ${ }^{4}$
Correspondence: Michael A. Erdek, M.D. 550 N. Broadway, Suite 301

Baltimore, MD 2/205

Email merdek@jhmi.edu

Zafeer B. Baber, M.D.

550 N. Broadway, Suite 301

Baltimore, MD 2। 205

Email zbaberI@jhmi.edu 
Table I FBSS statistics

Rajaee et $\mathrm{al}^{3}$

- $170.9 \%$ increase of primary lumbar fusions from 77,682 to 210,407 between 1998 and 2008

- II.3\% increase in laminectomies from 92,390 to 107,790 between 1998 and 2008

Parker et $\mathrm{al}^{6}$

- $5 \%-36 \%$ recurrence rate of back or leg pain 2 years after discectomy for disc herniation

Skolasky et $\mathrm{al}^{7}$

- $29.2 \%$ of patients had same or increased pain 12 months after surgical laminectomy for lumbar stenosis secondary to degenerative changes Arts et $\mathrm{al}^{24}$

- $35 \%$ success rate in terms of perceived recovery, functional disability, and pain. I5 months after instrumented fusion for treatment of FBSS

Abbreviation: FBSS, failed back surgery syndrome.

Patients with FBSS have had chronic longstanding back pain, with or without referred or radicular symptoms and have had one or more surgical interventions that have failed to treat the pain. Unfortunately, this happens all too often, with conservative estimates at $20 \%$ but other estimates as high as $40 \% .{ }^{5}$ A recent systematic literature review of discectomies for lumbar disc herniation in patients under the age of 70 years demonstrated a range of recurrent back or leg pain in $5 \%-36 \%$ of patients after 2 years. ${ }^{6}$ Another prospective study by Skolasky et $\mathrm{al}^{7}$ involving 260 patients who underwent a surgical laminectomy with or without fusion for lumbar spinal stenosis secondary to degenerative changes demonstrated that $29.2 \%$ of patients had either no change or increased pain after 12 months. Improved outcomes associated with FBSS will rely more on comprehensive knowledge of the physician in order to effectively prevent, diagnose, and treat FBSS.

\section{Etiology}

FBSS may be caused by a multitude of reasons including both preoperative and postoperative risk factors (Table 2).

\section{Preoperative factors}

Many preoperative indicators determine the likelihood of success of spinal surgery. Such indicators include the accuracy of diagnoses, socioeconomic, behavioral, and psychological factors.

Successful outcome of a surgical intervention is dependent on the accurate diagnosis of the patient's etiology of pain. For example, the decision to undergo surgery and the type of surgery performed are different if the patient's pain is derived from a herniated disc versus spondylolisthesis. Inaccurate diagnosing is a major factor leading to FBSS, with as much as $58 \%$ of FBSS resulting from undiagnosed lateral stenosis of the lumbar spine. ${ }^{8}$ Certain diagnoses are associated with greater rates of FBSS. For example, multiple studies have shown that back pain caused by foraminal stenosis is associated with greater rates of FBSS than pain caused by recurrent disc herniation. ${ }^{8-11}$ Entrapment of the superior cluneal nerve
Table 2 Summary of factors leading to failed back surgery syndrome

\begin{tabular}{ll}
\hline Preoperative factors & Postoperative factors \\
$\begin{array}{l}\text { Litigation, worker's } \\
\text { compensation }\end{array}$ & $\begin{array}{l}\text { Progression of degenerative changes } \\
\text { (new onset foraminal stenosis, new/ } \\
\text { recurrent disc herniation) } \\
\text { Smoking }\end{array}$ \\
$\begin{array}{l}\text { Altered biomechanics leading to } \\
\text { joint leading, muscular hypertrophy, } \\
\text { atrophy, and spasms }\end{array}$ \\
$\begin{array}{l}\text { Obesity } \\
\text { Preoperative psychiatric disorders } \\
\text { (depression and anxiety) } \\
\text { Etiology of back pain (foraminal } \\
\text { stenosis > disc herniation) }\end{array}$ \\
\hline
\end{tabular}

is an often overlooked diagnosis in patients presenting with lower back pain with or without leg symptoms. ${ }^{12}$ Accurate diagnosis is dependent on a thorough history, physical examination, and imaging. Diagnostic injections can be used to further clarify the sources of back and leg pain.

Economic influences that may act to prevent successful spinal surgical outcomes include litigation and workers' compensation. These factors create the confounding variable of secondary gain that may hinder the patient's motivation to improve. Multiple studies have demonstrated that patients receiving workers' compensation respond poorly to spine surgeries compared with nonworkers' compensation in nearly all outcome variables including postoperative pain levels, postoperative opioid use, functional ability after surgery including ability to work, and overall emotional well-being. ${ }^{13-15}$

Behavioral factors may act to affect postoperative outcome after spine surgery. A large prospective cohort study involving 4,555 patients who had spine surgery for lumbar spinal stenosis demonstrated that smokers had a more regular use of analgesics, worsened walking ability, and inferior overall quality of life 2 years after surgery compared with nonsmokers. ${ }^{16}$ Smoking is also associated with an increased rate of perioperative complications such as impaired wound healing, increased rate of infections, and an increased rate of nonunion 
in spinal fusions. ${ }^{17-19}$ These results demonstrate the importance of encouraging behavioral modification in order to optimize the patient for postoperative success. This emphasis can be applied to multiple facets of life including maintenance of body habitus and optimization of emotional disposition prior to surgery. ${ }^{20,21}$ Optimization of this variable may require preoperative consultations with nutrition and physical medicine and rehabilitation to create healthy habits that will last into the postoperative phase of the patient's recovery.

Psychological evaluation to assess for these risks factors may play a key role in recognizing the predictive value of a patient's success after spinal surgery. Multiple studies have demonstrated that depression is one of the strongest prognostic indicators of a negative outcome after spinal surgery. Depressed patients generally feel more pain and weakness as well as return to work at significantly lower rates compared with their nondepressed counterparts. ${ }^{14,22}$ Depression, anxiety, and other psychological and social factors may be used to assess whether the patient is a good candidate for spinal surgery. As a result, the United States Preventative Service Task Force recommends a presurgical psychological screening; however, a majority of spinal surgeons do not use such an evaluation. ${ }^{23}$ More widespread use of preoperative psychological evaluations may play an important role in the prevention of FBSS.

\section{Postoperative factors}

The recurrence of back pain or the failure of back pain to resolve can be multifactorial in origin. Pain may result from further degeneration of the spinal column or new onset spinal pathology, or it can occur as a result of trauma or stress from adjacent muscles.

Back surgery often results in biomechanical changes within that region, resulting in an increased load burden within adjacent structures. This can accelerate degenerative changes in the areas of the spine both above and below the fusion. ${ }^{24}$ Fusion of the lumbar spine to the sacrum as well as fusion of multiple segments may lead to sacroiliac joint (SIJ) disease. ${ }^{25,26}$ Degenerative changes of the spine include facet arthropathy, which can cause new onset foraminal stenosis. Changes in the intervertebral discs include disc degeneration or a new onset herniated nucleus pulposus that can lead to central or foraminal stenosis. ${ }^{27}$ Stenosis can also be initiated or exacerbated by epidural adhesions that may eventually form after surgery. ${ }^{28}$

Altered biomechanics from back surgery may result in increased tension on the prevertebral and postvertebral muscles directly controlling movement of the spinal column.
Increased tension on these muscles can lead to stiffness, inflammation, spasms, and fatigue, which may all act to elicit pain in the paraspinal areas of the back. ${ }^{27}$ These muscles may also be directly traumatized during surgery as a result of intraoperative dissection and retraction. The odds of such an event occurring may be minimized by performing fusions using the anterior approach as well as with the use of minimally invasive surgeries..$^{29,30}$

\section{Diagnosis}

The assessment and diagnosis of FBSS always begins with eliciting a thorough history and physical examination (Table 3). The first step involves determining the severity and location of the pain. A temporal relationship between the pain and the surgery should be established. This information, compared to the patient's presurgical pain, can help elucidate a differential diagnosis. ${ }^{31}$ For example, presurgical radicular pain that persists in the immediate postoperative period may be indicative of a wrong site or incomplete surgery, whereas new onset radicular symptoms immediately after surgery may result from a misplaced screw that could warrant an immediate return to the operating room. New onset radicular symptoms in the acute postoperative period ( $1-5$ days) may also result from a hematoma or abscess.

Longstanding pain after surgery may not be as emergent as in the acute phase but is often more difficult to assess. Physical examination findings may help create a differential diagnosis, but they are often not reliable in establishing a clear diagnosis. The only clinical examination finding that

Table 3 Diagnostic modalities for FBSS

\begin{tabular}{ll}
\hline Modality & Comments \\
\hline History and physical & $\begin{array}{l}\text { Assess for radicular symptoms, range of } \\
\text { motion, paraspinal and SIJ tenderness, } \\
\text { alleviating and exacerbating factors } \\
\text { Assess for bony spinal deformities with }\end{array}$ \\
X-ray & $\begin{array}{l}\text { flexion and extension images } \\
\text { Gadolinium-enhanced TI is Gold standard } \\
\text { for assessing soft tissue injuries. Assess for } \\
\text { disc herniations, stenosis, and fibrosis }\end{array}$ \\
Useful when implanted hardware creates \\
CT myelogram & $\begin{array}{l}\text { artifact with MRI } \\
\text { Assess for osseous changes in the spine. }\end{array}$ \\
reconstructions & Helpful for visualization of hardware \\
Discography & $\begin{array}{l}\text { Helpful in isolating a specific intervertebral } \\
\text { disc as source of back/leg pain } \\
\text { Helpful in ruling in/out a specific nerve }\end{array}$ \\
Diagnostic injections & root or joint as cause of pain. Steroids \\
& may be added to provide sustained relief
\end{tabular}

Abbreviations: CT, computed tomography; FBSS, failed back surgery syndrome; MRI, magnetic resonance imaging; SIJ, sacroiliac joint. 
correlates with facet arthropathy is paraspinal tenderness. ${ }^{32}$ Unfortunately, paraspinal tenderness is also a major clinical examination finding for myofascial pain. In addition, myofascial referred pain can be mistaken for radicular pain on physical examination. ${ }^{33}$ Discogenic pain may also present as either radicular or nonradicular pain. Because of the limitations of the physical examination, the practitioner must rely on other diagnostic modalities like imaging and diagnostic procedures.

\section{Imaging}

In terms of imaging, X-rays are a simple first step in the evaluation of chronic postoperative back pain. Full spine standing flexion and extension X-rays can be used to assess spinal deformities, changes in lordosis, and sagittal balance and can demonstrate spondylolisthesis even with normal magnetic resonance imaging (MRI) findings. ${ }^{34,35}$ Limitations of plain film X-rays include its inability to show the spine in three dimensions as well as its inability to display soft tissue, rendering plain films inadequate in visualizing postoperative adhesions, spinal stenosis, disc deformities, and nerve root impingement. ${ }^{31}$ These limitations may necessitate more advanced imaging.

The gold standard for visualization of the spine is Gadolinium-enhanced MRI. ${ }^{36}$ Gadolinium-enhanced T1-weighted images allow the practitioner to differentiate disc herniation from postsurgical fibrosis as a cause of back pain. ${ }^{37}$ Although MRI is the preferred imaging modality for soft tissue visualization, computed tomography (CT) is helpful in visualizing osseous changes within the spine including facet changes and assessing the osseous dimensions of the canals. ${ }^{38}$ Often times, both CT and MRI are needed for optimum evaluation of the spine, but in cases where MRI is contraindicated (implanted medical device or metal) or where implanted hardware creates artifact on MRI, CT myelography or discography may be needed. ${ }^{39}$

\section{Diagnostic procedures Diagnostic nerve blocks}

Nerve blocks can be used for both diagnostic and therapeutic purposes. Selective nerve root blocks with only local anesthetic have been done historically as a mode of diagnosis and as a predictive guideline for patients considering lumbar decompression surgery despite its accuracy having been questioned. ${ }^{40,41}$ Adding steroid to local anesthetic can improve the duration of pain relief of injections, thus many injections can be both diagnostic and therapeutic. In some patients, both intra-articular

(IA) and extra-articular (EA) injections may provide relief for those suffering from SIJ pain (Figure 1). Consequently, the efficacy of IA versus EA injection is controversial. ${ }^{42}$

Diagnostic blocks of the facet joints have been done historically by two approaches; either by blocking the medial branches (MBs) innervating the joint or by directly injecting local anesthetic into the joint. It is widely considered that medial branch block (MBB) is a superior approach since in some patients the facet can be aberrantly innervated by other nerves. This may be a reason why MBBs are considered to be more predictive of successful radiofrequency ablation (RFA), although there have been no head to head studies directly comparing the two (Figure 2). ${ }^{32}$

\section{Management of FBSS}

The approach toward FBSS involves conservative management that first followed minimally invasive procedures, including injections, and finally surgical options as a last line therapy. In general, revision surgeries are not associated with

A

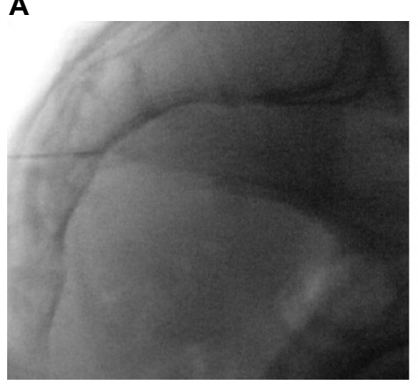

Figure I Sacroiliac joint injection.

Notes: Characteristic lateral (A) and AP (B) intra-articular sacroiliac joint (SIJ) injection. SIJ pain frequently occurs with lumbosacral fusion. The procedure can be used for both diagnostic and therapeutic purposes.

Abbreviation: AP, anteroposterior.
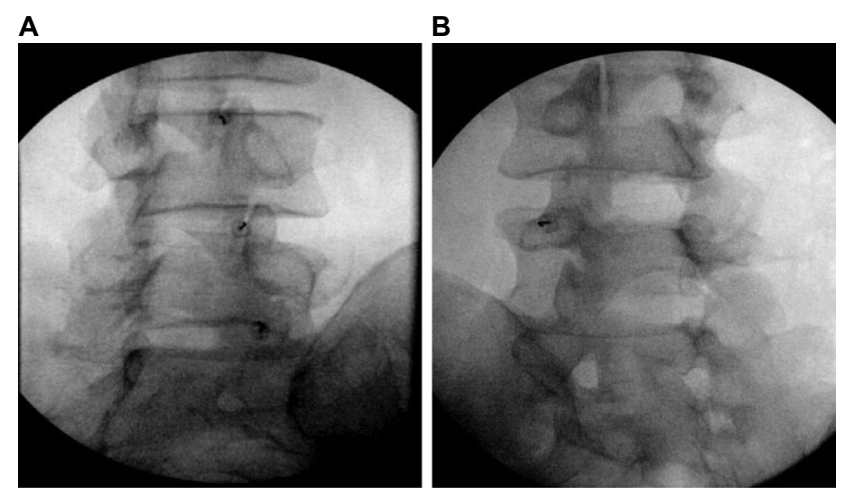

Figure 2 Facet joint interventions.

Notes: Fluoroscopic images of intra-articular facet blocks $(\mathbf{A})$ and a lumbar medial branch block (B). Both the procedures are used as a prognostic indicator for a medial branch radiofrequency ablation. Debate as to which procedure is more accurate remains controversial. 
improved pain scores and have a higher rate of comorbidities including increased bleeding, infections, acute respiratory distress syndrome, and longer hospital stays and even have higher mortality rates than the primary surgeries. ${ }^{43}$ Careful consideration of the type of therapy most appropriate for the treatment of FBSS is dependent on the etiology of the pain, likelihood that the intervention will succeed and the associated risks with the procedure. These risks include a return of symptoms and even an exacerbation of pain. All of these factors should be discussed with the patient and a consensus between the patient and physician should be made after careful consideration of the risks and benefits.

\section{Conservative management}

Physical therapy and medication management are the cornerstone of first-line management of FBSS. Physical therapy can help the patient optimize gait and posture and can improve muscle strength and physical function. ${ }^{44,45}$ Other conservative measures that may help postoperative back pain involve psychotherapy measures including stress reduction and cognitive behavioral therapy. ${ }^{46}$ Finally, noninvasive procedures including acupuncture and scrambler therapy can be used to minimize the pain associated with FBSS. ${ }^{47,48}$ These conservative measures should be done in conjunction with medication management to optimize pain relief.

\section{Pharmacological management}

Oral pharmacological treatment of FBSS is multimodal and increasingly controversial. Treatments include antiepileptics, Non-steroidal anti-inflammatory drugs, oral steroids, antidepressants, and opioids. Antiepileptics such as Gabapentin and Pregabalin can be used to treat neuropathic pain with FBSS and may play a role in preventing pain after surgery. ${ }^{49,50}$ Chronic opioid use is associated with a multitude of side effects including immunosuppression, androgen deficiency, constipation, and depression. Chronic opioid therapy for noncancer pain is associated with an increased morbidity and mortality and does not reliably improve long-term pain and function scores. As a result, there has been an increasing push by the government and medical community to minimize or even completely avoid the use of opioids for long-term pain. ${ }^{51}$

\section{Interventional pain procedures}

\section{Epidural injections}

Epidural steroid injections (ESIs) are the most commonly performed procedure in pain clinics around the world. ${ }^{52}$ These can be administered primarily by three approaches: transforaminal, interlaminar, or caudally, and are indicated for symptoms of radiculopathy. Radicular symptoms in the failed back patient may be due to a multitude of reasons including herniated disc, postoperative adhesions, a thickened ligamentum flavum, spondylolisthesis with or without an associated pars defect, osteophyte formation from facet arthropathy or other degenerative changes that may lead to central or transforaminal stenosis. ESI can be a useful tool for both treating the symptoms of radicular back pain after surgery and preventing or delaying the need for surgery. A recent meta-analysis suggests that between one-third and one-half of patients considering surgery for spinal pain can avoid it in the short term with ESI, although the evidence for this is stronger in patients who have not had prior surgery. ${ }^{53}$ In a separate retrospective study involving 69 patients with persistent radicular pain after back surgery, $26.8 \%$ of patients had at least $50 \%$ pain relief after transforaminal ESI. This number increased to $43 \%$ in patients with recurrent disc herniation.

Optimization of analgesia with ESIs in patients with FBSS can be achieved when performed in conjunction with pharmacologic agents aimed at treating neuropathic pain. Zencirci et al ${ }^{54}$ demonstrated that adding Gabapentin to ESI in patients with FBSS from at least two prior surgeries for lumbar disc herniation had significantly lower pain levels at 1 and 3 months compared with those who received ESI while taking naproxen sodium, tizanidine, and vitamin $\mathrm{B}$ and $\mathrm{C}$ complex. ${ }^{54}$ This study underlies the importance of a multimodal approach to treating FBSS.

\section{Adhesiolysis}

Postoperative scar formation is a natural part of tissue healing after any surgery. Naturally, spine surgery will result in the formation of fibrotic adhesions within the epidural space. These adhesions may cause back and leg pain by compressing nerve roots, decreasing range of motion in the back and inducing pain with movement. Adhesions may contribute to or cause $20 \%-36 \%$ of FBSS cases and may act to compromise the efficacy of ESI by creating septations within the epidural space that prevent steroid from acting on its intended target. ${ }^{31,55}$ Adhesions can theoretically be lysed, thereby improving baseline pain scores and drug delivery of the ESI. Lysis of adhesions typically occurs by delivering hyaluronidase with hypertonic saline into the epidural space. The use of hyaluronidase with steroid may be more effective and have longer duration of effect than either one alone. ${ }^{56}$ Lysis of adhesion can also be done by means of 
epiduroscopy, which may allow the physician to directly visualize the adhesions in the epidural space. In a systematic review performed by Helm et al, ${ }^{57}$ seven randomized control trials and three observational studies of 45 studies that met criteria demonstrated that Level I or strong evidence that percutaneous lysis of adhesions is efficacious in the treatment of chronic back and extremity pain, with weaker Level II or III evidence for epiduroscopy based on one RCT and three observational studies.

\section{Radiofrequency ablation}

RFA of nerves are often used to provide sustained relief that a diagnostic block or therapeutic injection cannot provide. Successfully targeting the intended nerve is achieved, maximizing the size of the lesion. This can be done by performing multiple RFA in different locations, increasing the temperature and time of the ablation, using bipolar RF or cooled $\mathrm{RF}^{42,58}$ As stated earlier, MBB or facet blocks are used as a diagnostic tool for facet-mediated pain. After a positive response, an RFA of the corresponding MBs is expected to provide pain relief for 6-12 months up to 2 years. ${ }^{59}$ As mentioned earlier, SIJ injections can be used for both diagnostic and therapeutic purposes with the addition of steroid often being used to prolong the analgesic effect. Patients who get effective but short-term relief from SIJ injections are optimal candidates for RFA of the S1-S3 lateral branches and L5 dorsal ramus innervating the SIJ. ${ }^{42}$

\section{Neuromodulation}

Spinal cord stimulation (SCS) is a treatment modality that has shown tremendous potential in the management of FBSS. The advent of SCS came just 2 years after Melzak and Wall's 1965 groundbreaking paper on Gate Theory with Shealy and Mortimer's case study on the complete elimination of pain in a 70-year-old male with metastatic bronchogenic carcinoma by means of electrical stimulation of the dorsal columns. ${ }^{60,61}$ Today, the technology of SCS is more refined, and the proposed mechanism of how SCS works is believed to be more complex than just gate theory mechanics. It has been proposed that SCS-induced analgesia occurs not only by its effects on the spinal cord but supraspinal components of the central nervous system as well as by inducing descending inhibitory pathways and inhibiting pain facilitation. ${ }^{62}$

The utility of SCS for pain associated with FBSS has been well-studied. The Prospective Randomized Controlled Multicenter Trial of the Effectiveness of Spinal Cord
Stimulation demonstrated improved outcomes with SCS compared with conventional medical medicine (CMM) alone in the treatment of neuropathic pain from FBSS. Metric measures included pain scores, quality of life, functional capacity, and patient satisfaction. ${ }^{63}$ More recently in the PRECISE Study, Zucco et $\mathrm{al}^{64}$ performed an observational, multicenter, longitudinal ambispective study on 80 patients with FBSS with predominant leg pain refractory to CMM and followed them for up to 24 months after SCS. Although total societal costs increased after SCS placement, the authors concluded that SCS implantation would be costeffective in $80 \%-85 \%$ when adjusting for quality-adjusted life years. This study underscores the continued costs of untreated FBSS on society as a whole, including loss of productivity, costs associated with disability, emergency room visits, imaging costs, and costs of medications and hospitalizations. ${ }^{64}$ Future studies include the Prospective, randomized study of multicolumn implantable lead stimulation for predominant low back pain (PROMISE) Study, which is a multicenter, prospective, randomized trial comparing SCS + CMM with CMM alone in patients with FBSS and predominantly lower back pain. The study aims to compare the outcomes such as pain scores, functional disability, return to work, and functional utilization between the two groups. Recruitment will end in 2016. ${ }^{65}$ Improved outcomes with FBSS will be expected with improving neuromodulation activities including "Burst" technology, higher frequency stimulation including $10 \mathrm{kHz}$, dorsal root ganglion stimulation, and peripheral nerve field stimulation (Table 4).

\section{Considerations for surgical revision}

As mentioned earlier, surgical revision for FBSS is associated with a high morbidity with corresponding low rates of success. Arts et $\mathrm{al}^{24}$ demonstrated only a $35 \%$ success rate 15 months after an instrumented fusion for the treatment of FBSS. These poor results demonstrate that the surgical option for the treatment of FBSS should be limited to last line therapy. With that being said, there are times when reoperation is mandated, such as loss of bowel or bladder function, motor weakness, and progressive neurological impairments from spinal cord injury, with relative indications being severe incapacitating radiculopathy, pseudoarthrosis, instability, and surgical hardware malfunction (Table 5). ${ }^{39,69}$

\section{Disclosure}

The authors declare no conflicts of interest in this work. 
Table 4 Neuromodulation studies

\begin{tabular}{|c|c|c|c|c|}
\hline Study & Participants & Method & Results & Comments \\
\hline $\begin{array}{l}\text { Kumar et al }{ }^{63} \\
\text { PROCESS trial }\end{array}$ & $\begin{array}{l}\text { I00 patients } \geq 18 \text { years who } \\
\text { had a history of radicular pain } \\
\text { in legs for at least } 6 \text { months } \\
\text { and at least one anatomically } \\
\text { successful surgery for HNP }\end{array}$ & $\begin{array}{l}\text { Group I: CMM alone } \\
\text { Group II: SCS and CMM } \\
\text { combined }\end{array}$ & $\begin{array}{l}\text { At } 6 \text { and } 12 \text { months, Group II, } \\
\text { Group I percentage of significant } \\
\text { pain relief }\end{array}$ & $\begin{array}{l}\text { An extensive study in support } \\
\text { of SCS for FBSS treatment }\end{array}$ \\
\hline $\begin{array}{l}\text { Zucco et al }{ }^{64} \\
\text { PRECISE Study }\end{array}$ & $\begin{array}{l}80 \text { FBSS patients with } \\
\text { predominant leg pain } \\
\text { refractory to CMM expecting } \\
\text { to receive SCS + CMM }\end{array}$ & $\begin{array}{l}\text { Collected data up to } 24 \\
\text { months after SCS in nine } \\
\text { Italian Centers regarding } \\
\text { pain, disability, HRQoL, and } \\
\text { health care-related costs } \\
\text { before and after SCS }\end{array}$ & $\begin{array}{l}\text { Decreased pain and disability, } \\
\text { greater HRQoL. Increased costs } \\
\text { from } € 6,600 \text { pre-SCS to } € \mid 3,200 \\
\text { post-SCS }\end{array}$ & $\begin{array}{l}\text { When adjusting for QALYs, } \\
\text { SCS implantation cost-effective } \\
\text { in } 80 \%-85 \% \text { of cases }\end{array}$ \\
\hline de Vos et $\left.a\right|^{66}$ & $\begin{array}{l}48 \text { patients with conventional } \\
\text { tonic-clonic stimulation for at } \\
\text { least } 6 \text { months }\end{array}$ & $\begin{array}{l}\text { Group I: painful diabetic } \\
\text { polyneuropathy } \\
\text { Group II: FBSS } \\
\text { Group III: FBSS who had } \\
\text { successful trial but had } \\
\text { reversion of pain over time }\end{array}$ & $\begin{array}{l}\text { Group I: significant pain reduction } \\
\text { in } 44 \% \text { of patients with burst. } \\
\text { Group II: significant pain reduction } \\
\text { in } 28 \% \text { of patients with burst. } \\
\text { Group III: marginal but statistically } \\
\text { significant improvement with burst }\end{array}$ & $\begin{array}{l}\text { Burst can help with further } \\
\text { pain reduction than tonic } \\
\text { stimulation }\end{array}$ \\
\hline Schu et $a^{67}$ & $\begin{array}{l}20 \text { patients with FBSS and } \\
\text { preexisting SCS }\end{array}$ & $\begin{array}{l}\text { Each patient received } 500 \text { - } \\
\mathrm{Hz} \text { tonic stimulation, burst } \\
\text { stimulation, and placebo } \\
\text { stimulation for I week each } \\
\text { at random }\end{array}$ & $\begin{array}{l}\text { Lowest NRS and SFMPQ scores } \\
\text { with burst }\end{array}$ & $\begin{array}{l}\text { Burst leads to significantly } \\
\text { better pain relief than tonic } \\
\text { and placebo for FBSS }\end{array}$ \\
\hline Lad et $\mathrm{al}^{68}$ & $\begin{array}{l}\text { Study cohort of } 16,455 \\
\text { patients with FBSS including } \\
395 \text { undergoing SCS }\end{array}$ & $\begin{array}{l}\text { Propensity score methods } \\
\text { used to match SCS with } \\
\text { those who got lumbar } \\
\text { reoperation }\end{array}$ & $\begin{array}{l}\text { Significantly lower complication } \\
\text { rates at } 90 \text { days post-op, } \\
\text { decreased hospital stay and } \\
\text { associated charges with similar } \\
\text { outpatient, medication and } \\
\text { emergency room charges }\end{array}$ & $\begin{array}{l}\text { SCS remains underused in } \\
\text { FBSS. Decreased complications } \\
\text { and improved outcomes } \\
\text { compared to reoperation } \\
\text { make SCS appealing }\end{array}$ \\
\hline
\end{tabular}

Note: Data from Hussain and, Erdek. ${ }^{39}$

Abbreviations: CMM, conventional medical management; FBSS, failed back surgery syndrome; HNP, herniated nucleus pulposus; HRQoL, health-related quality of life; NRS, numerical rating scale; PROCESS, Prospective Randomized Controlled Multicenter Trial of the Effectiveness of Spinal Cord Stimulation; QALYs, quality-adjusted life years; SCS, spinal cord stimulation; SFMPQ, Short-Form McGill Pain Questionnaire.

Table 5 Indications for revision surgery

\begin{tabular}{ll}
\hline Absolute indications & Relative indications \\
\hline $\begin{array}{l}\text { Impairment of bowel or } \\
\text { bladder functioning }\end{array}$ & $\begin{array}{l}\text { Severe sciatica that persists or worsens } \\
\text { despite } 4 \text { weeks of complete bed rest } \\
\text { Profound motor weakness } \\
\text { Recurrent episodes of incapacitating } \\
\text { sciatica }\end{array}$ \\
$\begin{array}{l}\text { Progressive neural deficit } \\
\text { despite complete bed rest }\end{array}$ & $\begin{array}{l}\text { Pseudarthrosis or instability } \\
\text { Problems associated with surgical } \\
\text { hardware such as screws or rods }\end{array}$ \\
\hline
\end{tabular}

Note: Reproduced with permission from Pain Practice. Hussain A, Erdek M. Interventional pain management for failed back surgery syndrome. 2014;14(1):64-78. John Wiley and Sons..$^{39} \odot 2013$ The Authors Pain Practice @ 2013 World Institute of Pain.

\section{References}

1. Hoy D, March L, Brooks P, et al. The global burden of low back pain: estimates from the Global Burden of Disease 2010 study. Ann Rheum Dis. 2014;73(6):968-974.

2. Smith M, Davis MA, Stano M, Whedon JM. Aging baby boomers and the rising cost of chronic back pain: secular trend analysis of longitudinal Medical Expenditures Panel Survey data for years 2000 to 2007. J Manipulative Physiol Ther. 2013;36(1):2-11.

3. Rajaee SS, Bae HW, Kanim LE, Delamarter RB. Spinal fusion in the United States: analysis of trends from 1998 to 2008. Spine. 2012;37(1):67-76.
4. Harvey AM. Classification of chronic pain-descriptions of chronic pain syndromes and definitions of pain terms. Clin J Pain. 1995;11(2):163.

5. Thomson S. Failed back surgery syndrome - definition, epidemiology and demographics. Br J Pain. 2013;7(1):56-59.

6. Parker SL, Mendenhall SK, Godil SS, Sivasubramanian P, Cahill K, Ziewacz J, McGirt MJ. Incidence of low back pain after lumbar discectomy for herniated disc and its effect on patient-reported outcomes. Clin Orthop Relat Res. 2015;473(6):1988-1999.

7. Skolasky RL, Wegener ST, Maggard AM, Riely LH 3rd. The impact of reduction of pain after lumbar spine surgery: the relationship between changes in pain and physical function and disability. Spine. 2014;39(17):1426-1432.

8. Burton CV, Kirkaldy-Willis WH, Yong-Hing K, Heithoff KB. Causes of failure of surgery on the lumbar spine. Clin Orthop Relat Res. 1981;157:191-199.

9. Schofferman J, Reynolds J, Herzog R, Covington E, Dreyfuss P, O’Neill C. Failed back surgery: etiology and diagnostic evaluation. Spine J. 2003;3(5):400-403.

10. Waguespack A, Schofferman J, Slosar P, Reynolds J. Etiology of longterm failures of lumbar spine surgery. Pain Med. 2002;3(1):18-22.

11. Slipman CW, Shin CH, Patel RK, et al. Etiologies of failed back surgery syndrome. Pain Med. 2002;3(3):200-214.

12. Kuniya H, Aota Y, Kawai T, Kaneko K, Konno T, Saito T. Prospective study of superior cluneal nerve disorder as a potential cause of low back pain and leg symptoms. J Orthop Surg Res. 2014;9(1):1.

13. Gum JL, Glassman SD, Carreon LY. Is type of compensation a predictor of outcome after lumbar fusion? Spine. 2013;38(5):443-448. 
14. Anderson JT, Haas AR, Percy R, Woods ST, Ahn UM, Ahn NU. Clinical depression is a strong predictor of poor lumbar fusion outcomes among workers' compensation subjects. Spine. 2015;40(10):748-756.

15. Nguyen TH, Randolph DC, Talmage J, Succop P, Travis R. Long-term outcomes of lumbar fusion among workers' compensation subjects: a historical cohort study. Spine. 2011;36(4):320-331.

16. Sandén B, Försth P, Michaëlsson K. Smokers show less improvement than nonsmokers two years after surgery for lumbar spinal stenosis: a study of 4555 patients from the Swedish spine register. Spine. 2011; 36(13):1059-1064.

17. Krueger JK, Rohrich RJ. Clearing the smoke: the scientific rationale for tobacco abstention with plastic surgery. Plast Reconstr Surg. 2001; 108(4):1063-1073.

18. Fang A, Hu SS, Endres N, Bradford DS. Risk factors for infection after spinal surgery. Spine. 2005;30(12):1460-1465.

19. Glassman SD, Anagnost SC, Parker A, Burke D, Johnson JR, Dimar JR. The effect of cigarette smoking and smoking cessation on spinal fusion. Spine. 2000;25(20):2608-2615.

20. Marquez-Lara A, Nandyala SV, Sankaranarayanan S, Noureldin M, Singh K. Body mass index as a predictor of complications and mortality after lumbar spine surgery. Spine. 2014;39(10):798-804.

21. Menendez ME, Neuhaus V, Bot AG, Ring D, Cha TD. Psychiatric disorders and major spine surgery: epidemiology and perioperative outcomes. Spine. 2014;39(2):E111-E122.

22. McKillop AB, Carroll LJ, Battié MC. Depression as a prognostic factor of lumbar spinal stenosis: a systematic review. Spine J. 2014;14(5):837-846.

23. Young AK, Young BK, Riley LH 3rd, Skolasky RL. Assessment of presurgical psychological screening in patients undergoing spine surgery: use and clinical impact. J Spinal Disord Tech. 2014;27(2):76-79.

24. Arts MP, Kols NI, Onderwater SM, Peul WC. Clinical outcome of instrumented fusion for the treatment of failed back surgery syndrome: a case series of 100 patients. Acta Neurochir 2012;154(7):1213-1217.

25. Unoki E, Abe E, Murai H, Kobayashi T, Abe T. Fusion of multiple segments can increase the incidence of sacroiliac joint pain after lumbar or lumbosacral fusion. Spine. Epub 2015 Dec 18.

26. Katz V, Schofferman J, Reynolds J. The sacroiliac joint: a potential cause of pain after lumbar fusion to the sacrum. J Spinal Disord Tech. 2003;16(1):96-99.

27. Rigoard P, Blond S, David R, Mertens P. Pathophysiological characterisation of back pain generators in failed back surgery syndrome (part B). Neurochirurgie. 2015;61(Suppl 1):S35-S44.

28. Hsu E, Atanelov L, Plunkett AR, Chai N, Chen Y, Cohen SP. Epidural lysis of adhesions for failed back surgery and spinal stenosis: factors associated with treatment outcome. Anesth Analg. 2014;118(1):215-224.

29. Zdeblick TA, David SM. A prospective comparison of surgical approach for anterior L4-L5 fusion: laparoscopic versus mini anterior lumbar interbody fusion. Spine. 2000;25(20):2682-2687.

30. Mobbs RJ, Sivabalan P, Li J. Minimally invasive surgery compared to open spinal fusion for the treatment of degenerative lumbar spine pathologies. J Clin Neurosci. 2012;19(6):829-835.

31. Chan C-w, Peng P. Failed back surgery syndrome. Pain Medicine. 2011;12(4):577-606.

32. Cohen SP, Huang JHY, Brummett C. Facet joint pain - advances in patient selection and treatment. Nat Rev Rheumatol. 2013;9(2):101-116.

33. Shapiro CM. The failed back surgery syndrome: pitfalls surrounding evaluation and treatment. Phys Med Rehabil Clin N Am. 2014;25(2): 319-340.

34. Assaker R, Zairi F. Failed back surgery syndrome: to re-operate or not to re-operate? A retrospective review of patient selection and failures. Neurochirurgie. 2015;61(Suppl 1):S77-S82.

35. Kizilkilic O, Yalcin O, Sen O, Aydin MV, Yildirim T, Hurcan C. The role of standing flexion-extension radiographs for spondylolisthesis following single level disk surgery. Neurol Res. 2007;29(6):540-543.

36. Desai MJ, Nava A, Rigoard P, Shah B, Taylor RS. Optimal medical, rehabilitation and behavioral management in the setting of failed back surgery syndrome. Neurochirurgie. 2015;61(Suppl 1):S66-S76.
37. Babar S, Saifuddin A. MRI of the post-discectomy lumbar spine. Clin Radiol. 2002;57(11):969-981.

38. Eun SS, Lee HY, Lee SH, Kim KH, Liu WC. MRI versus CT for the diagnosis of lumbar spinal stenosis. J Neuroradiol. 2012;39(2):104-109.

39. Hussain A, Erdek M. Interventional pain management for failed back surgery syndrome. Pain Practice. 2014;14(1):64-78.

40. Datta S, Manchikanti L, Falco FJ, et al. Diagnostic utility of selective nerve root blocks in the diagnosis of lumbosacral radicular pain: systematic review and update of current evidence. Pain Physician. 2013;16(2 Suppl): SE97-S124.

41. Beynon R, Hawkins J, Laing R, et al. The diagnostic utility and costeffectiveness of selective nerve root blocks in patients considered for lumbar decompression surgery: a systematic review and economic model. Health Technol Assess. 2013;17(19):1-88.

42. Cohen SP, Chen Y, Neufeld NJ. Sacroiliac joint pain: a comprehensive review of epidemiology, diagnosis and treatment. Expert Rev Neurother. 2013;13(1):99-116.

43. Diebo BG, Passias PG, Marascalchi BJ, Jalai CM, Worley NJ, Errico TJ, Lafage V. Primary versus revision surgery in the setting of adult spinal deformity: a nationwide study on 10,912 patients. Spine. 2015;40(21): 1674-1680.

44. Delitto A, Piva SR, Moore CG, et al. Surgery versus nonsurgical treatment of lumbar spinal stenosis: a randomized trial. Ann Intern Med. 2015;162(7):465-473.

45. Keller A, Brox JI, Gunderson R, Holm I, Friis A, Reikerås O. Trunk muscle strength, cross-sectional area, and density in patients with chronic low back pain randomized to lumbar fusion or cognitive intervention and exercises. Spine. 2004;29(1):3-8.

46. Cramer H, Haller H, Lauche R, Dobos G. Mindfulness-based stress reduction for low back pain. a systematic review. BMC Complement Altern Med. 2012;12(1):162.

47. Cho Y-H, Kim CK, Heo KH, et al. Acupuncture for acute postoperative pain after back surgery: a systematic review and meta-analysis of randomized controlled trials. Pain Pract. 2015;15(3):279-291.

48. Marineo G, Iorno V, Gandini C, Moschini V, Smith TJ. Scrambler therapy may relieve chronic neuropathic pain more effectively than guidelinebased drug management: results of a pilot, randomized, controlled trial. J Pain Symptom Manage. 2012;43(1):87-95.

49. Khosravi MB, Azemati S, Sahmeddini MA. Gabapentin versus naproxen in the management of failed back surgery syndrome; a randomized controlled trial. Acta Ancesthesiol Belg. 2014;65(1):31-37.

50. Canos A, Cort L, Fernández Y, Rovira V, Pallarés J, Barberá M, MoralesSuárez-Varela M. Preventive analgesia with pregabalin in neuropathic pain from "failed back surgery syndrome": assessment of sleep quality and disability. Pain Med. Epub 2015 Sep 23.

51. Katz JA, Swerdloff MA, Brass SD, Argoff CE, Markman J, Backonja M, Katz N. Opioids for chronic noncancer pain: a position paper of the American Academy of Neurology. Neurology. 2015;84(14):1503-1505.

52. Manchikanti L. The growth of interventional pain management in the new millennium: a critical analysis of utilization in the Medicare population. Pain Physician. 2004;7(4):465-482.

53. Bicket MC, Horowitz JM, Benzon HT, Cohen SP. Epidural injections in prevention of surgery for spinal pain: systematic review and meta-analysis of randomized controlled trials. Spine J. 2015;15(2): 348-362.

54. Zencirci B. Analgesic efficacy of oral gabapentin added to standard epidural corticosteroids in patients with failed back surgery. Clin Pharmacol. 2010;2:207-211.

55. Rahimzadeh P, Sharma V, Imani F, Faiz HR, Ghodraty MR, NikzadJamnani AR, Nader ND. Adjuvant hyaluronidase to epidural steroid improves the quality of analgesia in failed back surgery syndrome: a prospective randomized clinical trial. Pain Physician. 2014;17(1): E75-E82.

56. Kim SB, Lee KW, Lee JH, Kim MA, An BW. The effect of hyaluronidase in interlaminar lumbar epidural injection for failed back surgery syndrome. Ann Rehabil Med. 2012;36(4):466-473. 
57. Helm Ii S, Racz GB, Gerdesmeyer L, et al. Percutaneous and endoscopic adhesiolysis in managing low back and lower extremity pain: a systematic review and meta-analysis. Pain Physician. 2016;19(2):E245-E281.

58. Costandi S, Garcia-Jacques M, Dews T, et al. Optimal temperature for radiofrequency ablation of lumbar medial branches for treatment of facet - mediated back pain. Pain Pract. Epub 2015 Sep 15.

59. McCormick ZL, Marshall B, Walker J, McCarthy R, Walega DR. Long-Term Function, Pain and Medication Use Outcomes of Radiofrequency Ablation for Lumbar Facet Syndrome. Int J Anesth Anesth. 2015;2(2):pii:028.

60. Melzack R, Wall PD. Pain mechanisms: a new theory. Survey Anesth. 1967;11(2):89-90.

61. Shealy CN, Mortimer JT, Reswick JB. Electrical inhibition of pain by stimulation of the dorsal columns: preliminary clinical report. Anesth Analg. 1967;46(4):489-491.

62. Guan Y. Spinal cord stimulation: neurophysiological and neurochemical mechanisms of action. Curr Pain Headache Rep. 2012;16(3): 217-225.

63. Kumar K, Taylor RS, Jacques L, et al. Spinal cord stimulation versus conventional medical management for neuropathic pain: a multicentre randomised controlled trial in patients with failed back surgery syndrome. Pain. 2007;132(1):179-188.
64. Zucco F, Ciampichini R, Lavano A, et al. Cost-effectiveness and costutility analysis of spinal cord stimulation in patients with failed back surgery syndrome: results from the PRECISE study. Neuromodulation. 2015;18(4):266-276.

65. Rigoard P, Desai MJ, North RB, et al. Spinal cord stimulation for predominant low back pain in failed back surgery syndrome: study protocol for an international multicenter randomized controlled trial (PROMISE study). Trials. 2013;14(1):376.

66. de Vos CC, Bom MJ, Vanneste S, Lenders MW, de Ridder D. Burst spinal cord stimulation evaluated in patients with failed back surgery syndrome and painful diabetic neuropathy. Neuromodulation. 2014;17(2):152-159.

67. Schu S, Slotty PJ, Bara G, von Knop M, Edgar D, Vesper J. A prospective, randomised, double-blind, placebo-controlled study to examine the effectiveness of burst spinal cord stimulation patterns for the treatment of failed back surgery syndrome. Neuromodulation. 2014;17(5):443-450.

68. Lad SP, Babu R, Bagley JH, et al. Utilization of spinal cord stimulation in patients with failed back surgery syndrome. Spine. 2014;39(12): E719-E727.

69. Waddell G, Kummel EG, Lotto WN, Graham JD, Hall H, McCulloch JA Failed lumbar disc surgery and repeat surgery following industrial injuries. J Bone Joint Surg Am. 1979;61(2):201-207.

\section{Journal of Pain Research}

\section{Publish your work in this journal}

The Journal of Pain Research is an international, peer reviewed, open access, online journal that welcomes laboratory and clinical findings in the fields of pain research and the prevention and management of pain. Original research, reviews, symposium reports, hypothesis formation and commentaries are all considered for publication.

\section{Dovepress}

The manuscript management system is completely online and includes a very quick and fair peer-review system, which is all easy to use. Visit http://www.dovepress.com/testimonials.php to read real quotes from published authors. 